Temas del Arte

DOI: $10.26807 /$ cav.vi10.317

\title{
EL GRAFITI COMO UNA MANIFESTACIÓN URBANA EN LA CIUDAD DE PUNO
}

\section{GRAFFITI AS AN URBAN DEMONSTRATION IN THE CITY OF PUNO}

\section{Resumen}

El estudio en que se fundamentó este artículo tuvo como objetivo describir las características del arte grafitero en la ciudad de Puno, Perú en 2019. La investigación fue de tipo no experimental, cualitativa, descriptiva y analítica. Los instrumentos de recolección de datos fueron la ficha de observación y la cámara fotográfica. La tipología en los grafitis de la ciudad de Puno, se encontró tres tipos; el Wild Style, Grafiti tags con outlines y los Tags. Las corrientes artísticas que se lograron identificar como más influyentes sobre las obras de los grafiteros de Puno son el simbolismo, realismo, surrealismo y abstracto. La cosmovisión andina se hace presente en las obras de los grafiteros de Puno en la recurrente convocatoria de la mítica Pachamama en reflexión constante sobre su interacción con el hombre y cómo se expresa esa interrelación en escenarios disimiles de reciprocidad y/o antagonismo.

Palabras clave: Grafiti, arte, realismo, surrealismo, abstarcato, tag.

\section{Abstract}

The study on which this article was based describes the characteristics of graffiti art in the city of Puno, Peru 2019. The research was non-experimental, qualitative, descriptive, and analytical. The data collection instruments were the observation card and the camera. Three types of graffiti were found in the city of Puno: Wild Style, Graffiti tags with outlines, and tags. The artistic streams that were identified as influential on the works of Puno's graffiti artists are symbolism, realism, surrealism and abstract. The Andean cosmovision can be seen in their works in the recurring call of the mythical Pachamama in constant reflection on their interaction with man, and how this interrelationship is expressed in dissimilar scenarios of reciprocity and/or antagonism. 
Keywords: Graffiti, art, realism, surrealism, abstract, tag

\section{Biografía de los autores}

Wilber Cesar Calsina Ponce. Doctor en Ciencias Sociales. Facultad de Ciencias Sociales, Escuela Profesional de Arte. Universidad Nacional del Altiplano de Puno, Perú. wilber20calsina@gmail.com

Código de identificación ORCID: https://orcid.org/0000-0001-9094-7684

Benjamín Velazco Reyes. Doctor en Educación. Facultad de Ciencias Sociales, Escuela Profesional de Arte. Universidad Nacional del Altiplano Puno, Perú. benjaminvelazcopilco@gmail.com

Código de identificación ORCID: https://orcid.org/0000-0003-2780-786X

Sandra Imelda Huargaya Quispe. Magister en Arte. Ciencias Sociales, Escuela Profesional De Arte. Universidad Nacional del Altiplano Puno, Perú. andreimeldaquispe@gmail.com Código de identificación ORCID: https://orcid.org/0000-0001-9094-7684

\section{Introducción}

El grafiti en algunas metrópolis, como en el caso de Quito y Guayaquil (Anchundia y Chang, 2018) juegan un papel importante en la convivencia del arte urbano con la sociedad, considerando que el grafiti es un medio de expresión, cultural y social (Hernández L. , 2016), sin embargo no en todas las ciudades se desarrollaron de la misma manera, y es por ello que realizamos el estudio enfocado en la ciudad de Puno.

La importancia del grafiti en las sociedades radica en que la ciudadanía puede expresarse libremente sobre una gran variedad de temas (Quiroga, 2019), este arte es una de las expresiones de arte urbano y más característico de la actualidad (García, 2016), o como lo llama, (Ramirez R. , 2013) un sistema de comunicación icónica en toda sociedad moderna, que refleja un sentimiento de la colectividad (Ariaza \& Martinez, 2016). Al 
constituir una manifestación artística urbana, los grafiteros expresan lo que viven, sienten y piensan (Hidalgo, 2018-2019), dan a conocer sus mensajes sociales, políticos o de cualquier otra índole (Hernández L. , 2016). Aunque en algunos casos solo buscan dejar su huella (Cumpa, 2019), manifiesta la búsqueda del autorreconocimiento y la autovaloración. Los cambios en la vida urbana, generados por los medios de comunicación o por las tecnologías, han hecho aparecer nuevas configuraciones comunicacionales (Lopera, 2016). Dentro de esas renovadas formas se encuentran los grafitis que se posicionaron como herramientas de comunicación informal (Hernández L. , 2016), a través de la cual, los grafiteros difunden mensajes que permean visualmente a los espectadores.

Los orígenes del grafiti como expresión del arte urbano y callejero se ubican en las calles norteamericanas a comienzos de la segunda mitad del siglo XX (Cruz, 2008). El ámbito de expresión para los jóvenes negros, latinos, asiáticos y para los blancos pobres quienes se oponían al reclutamiento forzoso, el racismo, la pobreza y la guerra. Aunado a ello, la confluencia dentro de las mismas barridas de jóvenes quienes se agrupaban en bandas para conservar la integridad del barrio y/o delincuencia organizada generalmente asociado a drogas, prostitución, robos y atracos. Las bandas los amparaban y los criterios de identificabilidad y el sentido de pertenencia configuró formas de expresión en simbología propia del grupo. En New York la expresión grafitera se apoderó de los vagones del metro en ejercicio artístico contestatario desde la clandestinidad. El grafitero se identifica con una firma que le anonimiza frente al extraño y le identifica frente a su grupo.

El grafiti tomó las calles de ciudades como New York, Cincinnati y los Ángeles, desplegados en grandes o medianos diseños donde se expresaba la perspectiva del artista su realidad, opiniones, críticas e identificación. Surge como arte oculto amparado por la oscuridad de la noche que permitió ocupar espacios públicos y privados con mensajes icónicos e incluso si referentes para el espectador común, el writer firmaba con o (Cruz, 2008; De Diego, 1998). La teoría de las "Ventanas Rotas" (Wilson \& Kelling) durante décadas ha criminalizado al grafiti, catalogándolo de vandálico, por cuanto la campaña contra la delincuencia emprendida en los barrios pobres de New York se enfocó en el "rescate de los espacios públicos", siendo los grafitis y los grafiteros uno de los objetivos fundamentales de la campaña. Para Kellig y su equipo de consultores, el grafiti constituía una ventana rota en los vecindarios que alentaba el vandalismo. Esta percepción se extendió 
como perspectiva tergiversada y discriminatoria del fenómeno artístico emergente, que perseguía invisibilizar el contenido simbólico del grafiti.

De Diego (1997) inscrito dentro de la corriente de los estados de conciencia de Hannerz (1980) señaló que los conocimientos, valores, intereses y creencias -estados de conciencia- de cada sujeto devienen de las experiencias sociales y las mismas se expresan en las autorepresentaciones del artista. En ese mismo orden De Diego (1997) establece parámetros para el uso de las categorías de cultura y arte del grafiti donde la cultura expresa las manifestaciones sociales en obras y gestos de la sociedad, mientras que el arte devela las tramas de las relaciones sociales, con un dinamismo inherente a la dinámica del espectador quien flexibiliza el sentido de la obra al reflexionar sobre la misma. Es así como el artista grafitero desde los inicios en Filadelfía, New York, Los Ángeles, Cincinnati o en cualquier urbe donde se manifieste, expresa las formas de interrelación con el entorno del artista y el espectador interpreta la obra desde el foco de sus propias creencias distantes o próximas a las del creador. Es así como el grafiti de los años 70 creció de la mano del hip hop y la identificación de los grupos locales para con su espacio y dinámica sociocultural, otorgando significado a los elementos del entorno en los que se reconocían los jóvenes de los barrios pobres.

El arte grafitero traspasó los espacios de las grandes urbes norteamericanas, hasta alcanzar las principales ciudades de Latinoamérica como ciudad de México, Sao Paulo y Caracas, al tiempo que la música con la que se asociaba encontraba aceptación entre la juventud latina y del mundo (Gómez, 2014). El grafiti o pintada emerge en Latinoamérica, como expresión cultural y artística transgresora que brinda voz a las voces silenciadas de las barriadas, alejadas de la univocidad y visón universalista contemporánea (Barzuna, 2007, 132; Hernandez, 2016) replicándose, como instrumento comunicacional eficiente entre los excluidos y entre quienes piensan diferente (Melel, 2011). El despliegue grafitero en Latinoamérica se impregnó de cultura local e iconos históricos, encontrando referente en la corriente muralista en países como México donde los icónicos Diego Rivera, David Alfaro Siquieros y Clemente Orozco inspiraron los artistas callejeros en ciudad de México. En Argentina Rodolfo Franco, Alfredo Guido y Guillermo Butler dejaron su huella en las estaciones del tren subterráneo en Buenos Aires. En otros países latinoamericanos los referentes del grafitero se entrecruzan con lo histórico y el siempre presente realismo mágico que impregna las pintas de los grafiteros en Perú, Brasil, Colombia, Venezuela y Perú. 
El grafitero en las ciudades latinoamericanas asalta los espacios volcando una singular plástica que expresa la identificación con identidades que no se diluyen en el todo urbano, singularizando y distinguiendo a través del "tag”, lo propio de lo ajeno. En el caso particular del Perú, el grafitero despliega su arte en una suerte de entrecruzamiento desafiante de las formas estéticas que predominan en el arte de lo que fuera el antiguo virreinato. El grafitero peruano encontró en los espacios urbanos plataformas para visualizar la realidad más allá de los anclajes sociohistóricos donde se representa un ideario heroico y se desdibuja la realidad del sujeto peruano de orígenes incaicos, luchador y quien se reconoce en una cultura ancestral. Así el realismo mágico de los artistas peruanos del grafiti se desdobla en obras como las de Edwin Higuchi Fernández quien firma como Pésimo y es reconocido en la ciudad de Lima por la expresiva mirada de sus personajes, quienes se asombran, entristecen, observan o sueñan (López, 2018). De la mano de Elio Tupac el arte sincrético del grafitero se posicionó en las calles de Lima, Arequipa y Santiago de Chile encontrando la expresión sincrética del peruano dentro del entorno contemporáneo bombardeado de sonidos, formas y colores que el artista logra captar (Tupac, 2020).

La cosmovisión andina se hace presente en las obras de los grafiteros peruanos desdoblando al hombre dentro de la casa grande - pacha- la gran Pachamama, la Madre Mundo donde habitan todos los seres en interrelación permanente (Campohermoso, et al, 2015). Así el grafitero peruano expresa el sincretismo cultural del Perú contemporáneo, en representación simbólica de lo propio, lo mixto y la otredad. Reconoce las interacciones y los referentes que le identifican como crews - perteneciente a un grupo de grafiteros- o con la tag que le es propia. Es así como en un mismo país confluyen multiplicidad de expresiones grafiteras que se distinguen tanto por los crew a los que se adscribe como a las ciudades dónde se realizar la obra.

En ese contexto el objetivo de este estudio fue describir las características del arte grafitero en la ciudad de Puno, Perú 2019.

\section{Metodología de investigación}

Investigación no experimental, cualitativa, descriptiva y analítica (Hernández, Fernandez y Batista, 2014). El estudio comprende el recorrido por los espacios más representativos del arte grafitero en la ciudad de Puno, año 2019. Los instrumentos de recolección de datos 
fueron la ficha de observación y la cámara fotográfica. Se procedió al diseño de fichas donde fueron registrados datos como ubicación geográfica, técnica, corrientes, tipología del espacio - público o privado- artista, tag, crew, estado de la obra, fecha de creación y sobreposición de otras obras.

\section{Resultados.}

\section{El grafiti según sus tipologías.}

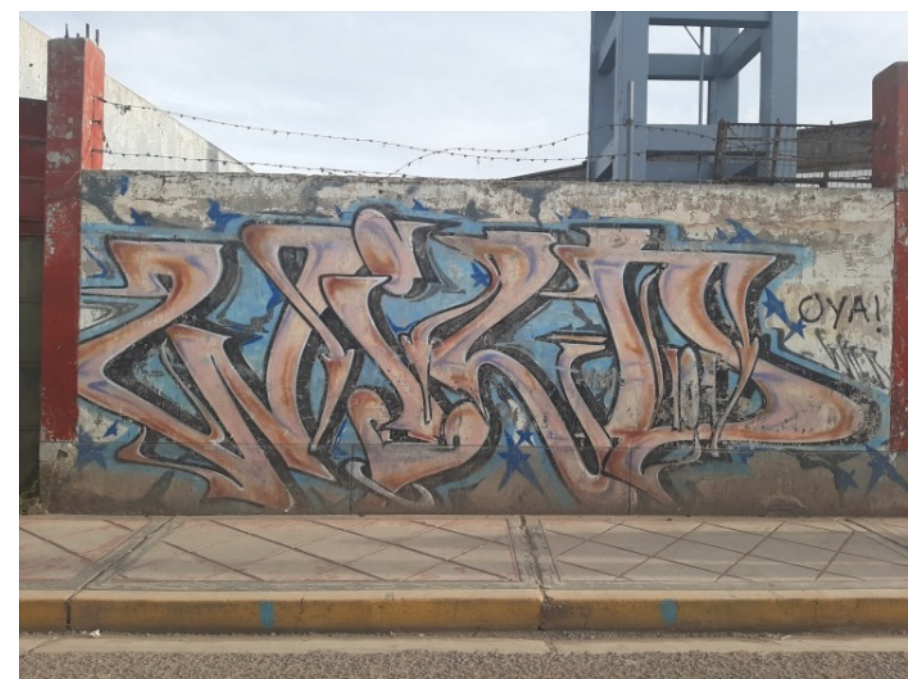

Figura 1. Grafiti de tipología, en el muro del estadio Enrique Torres Belón de Puno. Fotografía tomada por el investigador.

En el grafiti del estadio Enrique Torres Belón de Puno se aprecia la influencia de los grafiteros norteamericanos (figura 1). El trazo y el estilo en este trabajo de los crew autodenominados Wilds de Puno, se observa el tipo de grafiti denominado wild style, (Graffiti, 2020) que vendría a ser un estilo salvaje o desordenado, además sus terminaciones son con formas de flechas. La sobreposición de formas es lo dominante, generando la perspectiva del movimiento que capta el observador. 


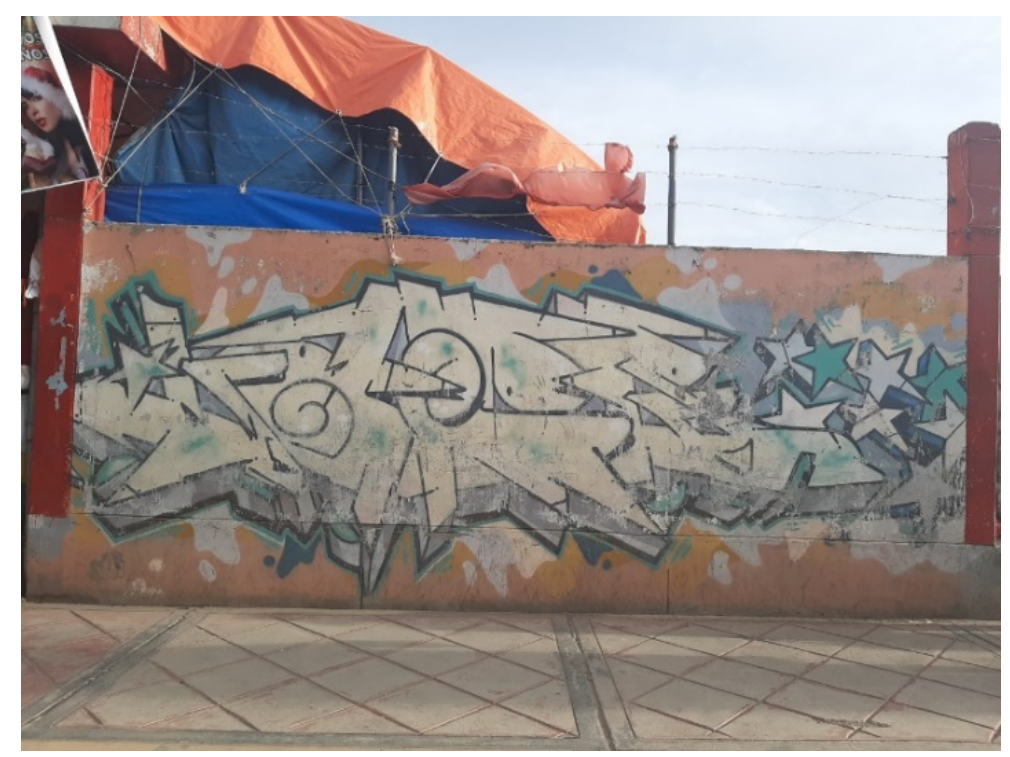

Figura 2. Grafiti abstracto, en el muro del estadio Enrique Torres Belón de Puno.

Fotografía tomada por el investigador

En este muro se puede apreciar un grafiti de tendencia abstracta (figura 2). El entrecruzamiento de líneas y formas dificulta la distinción de figuras o textos; por lo tanto, se denota solo los elementos plásticos.

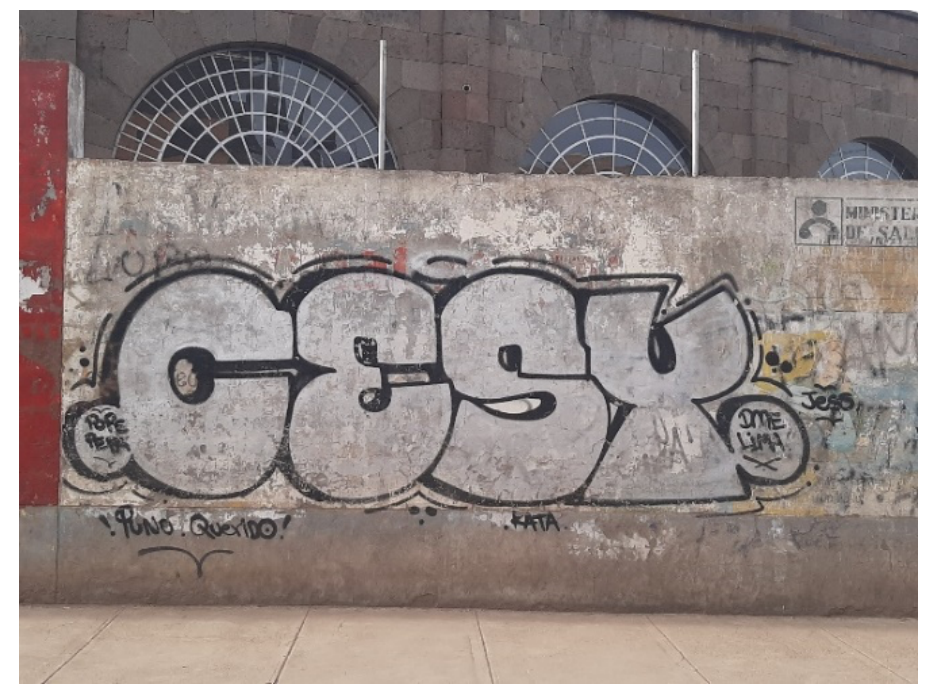

Figura 3. Grafiti tags con outlines, en el muro del estadio Enrique Torres Belón de Puno. Fotografía tomada por el investigador.

Este grafiti firmado por “.Kata” que está ubicado en el muro norte del estadio Enrique Torres Belón, se puede apreciar el texto “cesy” a una gran distancia (figura 3). El texto es grueso y los contornos son notorios; además, se observa que tiene un delineado externo lo que hace resaltar aún más el texto, al que se denomina en el mundo del grafiti como "Grafiti tags con outlines" (Graffiti, 2020). Según Cumpa (2019), los grafitis tienen determinadas condiciones que deben satisfacer entre ellos el significado monosémico, 
significa lo que dice, y, aunque es preciso, ese significado requiere la codificación para quienes no hablan determinada lengua, es decir, es entendida solo por quienes hablan ese idioma, salvo aquellas palabras o frases que tienen carácter universal, como las denominaciones de las ciudades, países, nombres propios etc.

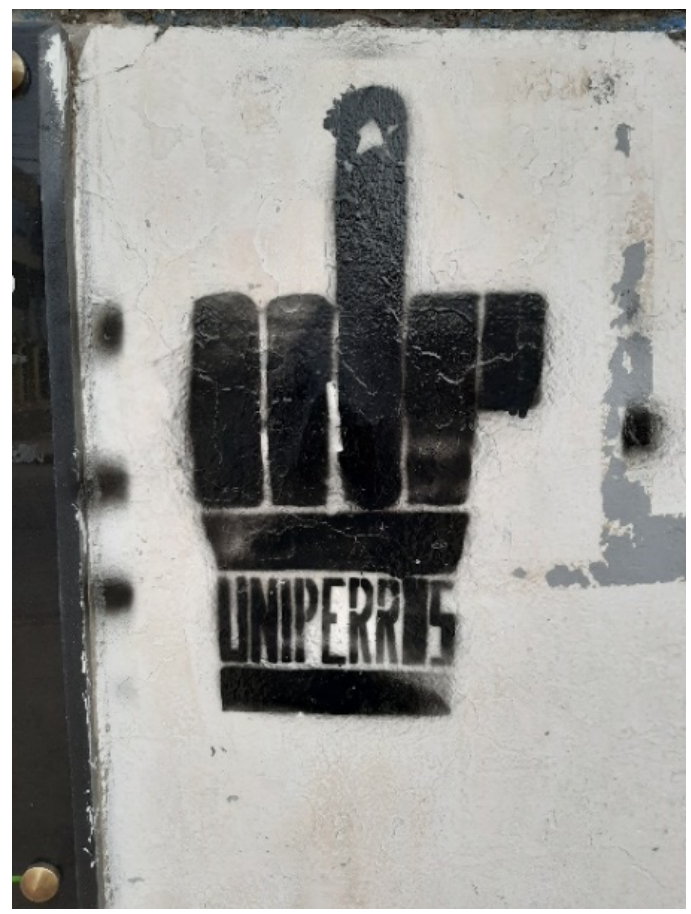

Figura 4. Grafiti con stencil, en el muro del estadio Enrique Torres Belón de Puno. Fotografía tomada por el investigador.

En Puno también se observa la técnica del esténcil o plantillismo en los grafitis (figura 4). Los grafiteros utilizan una plantilla de textos o imágenes, convergiendo o no texto e imágenes, con la limitante del tamaño estandarizado del grafiti lo que minimiza las posibilidades de construir obras de mayor tamaño. Se observa que los grafiteros realizaron una sintetización de la mano en base a la geometrización de las formas; igualmente, esta fue fragmentada considerando las partes de la mano. Por otro lado, sobre la tipología, se observa una geometrización del texto, la cual no presenta dificultad para leerlo, a pesar del alargamiento de este.

El recorrido por los espacios grafiteros de Puno, expresa el dominio de tres tipos de grafitis según su tipología: "Grafiti wild style", "Grafiti tags con outlines" y "El stencil”.

\section{Las corrientes o vanguardias adoptadas por los artistas.}

A nivel internacional hay diversas corrientes que siguen los grafiteros como es el caso surrealismo y el Dadaísmo (Agramunt, 2017). Para el caso de Puno, se identificó que 
las corrientes artísticas más sobresalientes son el simbolismo, realismo, surrealismo y el arte abstracto, no obstante, el surrealismo es el más notorio.

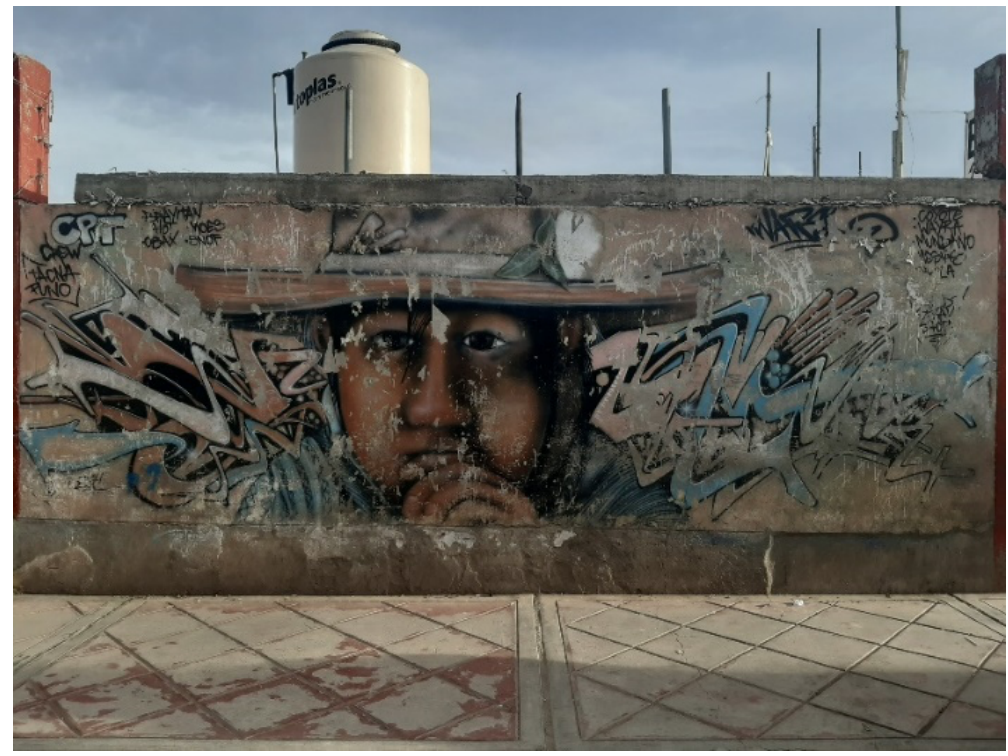

Figura 5. Grafiti realista y abstracto, en el muro del estadio Enrique Torres Belón de Puno. Fotografía tomada por el investigador.

En la figura 5 se aprecia la integración del realismo y el arte abstracto en el trabajo de "Wafe", ello se percibe en los rasgos faciales de la persona ubicada en el centro de la obra y rodeada por líneas y figuras superpuestas que otorgan libertad al espectador para interpretar el sentido de estas. Como primer plano se aprecia el retrato del poblador andino con un característico sombrero del hombre de la sierra que vive en el medio rural con los rasgos faciales característicos de las personas originarias de la región, en una construcción realista del personaje, quien en sus ojos mirando el vacío y las manos entrelazadas refiere la incertidumbre. En el fondo y a ambos lados del rostro se observan trazos y figuras zigzagueantes sobrepuestas y no definidas que se entrelazan entre sí, en lo que evoca sonidos que aturden al hombre ubicado al centro de la composición del grafiti. En síntesis, en este caso específico hay una dialogo visual entre dos corrientes que coexisten y que se fusionan visualmente. Para "Wafe" el grafiti es un medio de comunicación (Anchundia, 2018) que le permite expresar situaciones complejas en las que el habitante de la sierra es bombardeado de ruidos, e imágenes que le desconciertan e impelen a tomar decisiones y/o asumir modos de ser y hacer que no necesariamente son cónsonos con sus referenciales históricos y sociales. 


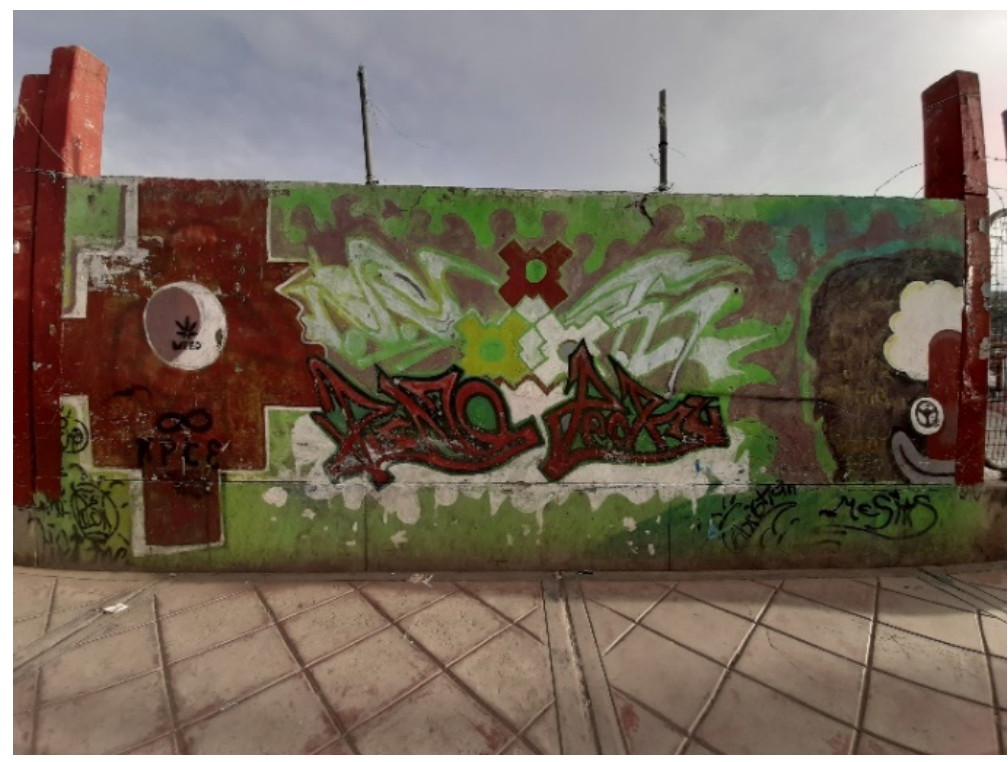

Figura 6. Grafiti de tendencia simbolista, en el muro del estadio Enrique Torres Belón de Puno. Fotografía tomada por el investigador.

En relación al simbolismo en la figura 6 se observa que los artistas de Puno recurren a elementos del misticismo y religiosidad incaicos, reproduciendo imágenes y formas que evocan personajes del imaginario colectivo precolombino. Así en el trazado del tag se observan las Palabras Puno y Xeoxiu, no obstante, al tomar distancia la perspectiva cambia apareciendo una forma aproximada de un animal mitológico. En la localidad persisten grafitis donde se distinguen elementos sintetizados, aplicando técnicas de geometrización de las formas naturales y creadas, como es el caso de la chacana y las indumentarias de la región altiplánica. Ello expresa la identidad cultural entre los grafiteros y la herencia histórica de la ciudad de Puno.

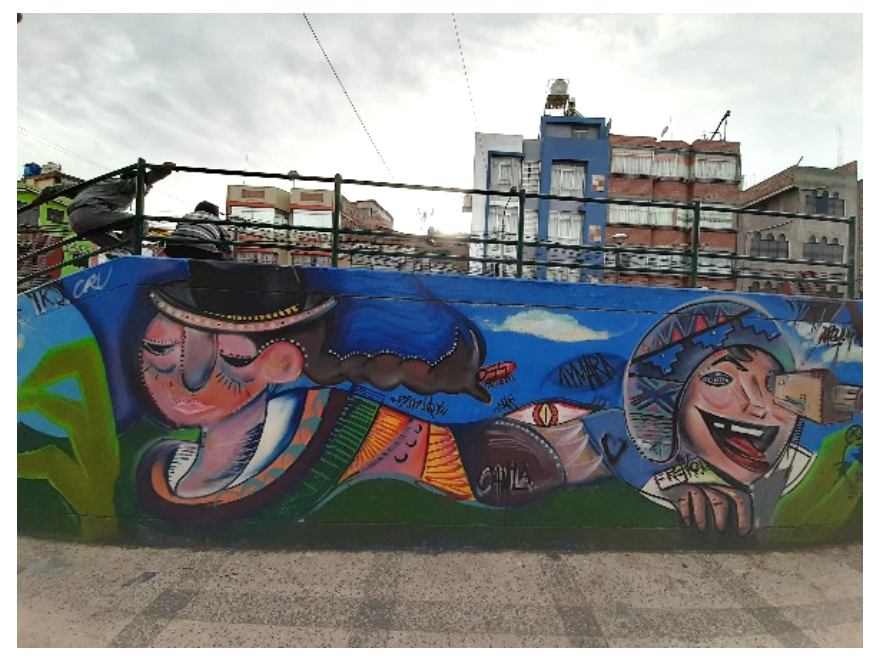

Figura 7. Grafiti surrealista, en el Jirón Progreso.

Fotografía tomada por el investigador. 
En la figura 7 corresponde a un grafiti firmado por "JKJ cru" se aprecia una escena surrealista donde prevalece lo absurdo por sobre la realidad. La Pachamama se desdobla en la figura de una mujer quien se alza por sobre las montañas en clama silente, mientras que, a su espalda, quien pareciera ser su hijo - representado por un niño enfundado en un gorro decorado con imágenes alegóricas de la cultura local- se asombra por lo que logra captar a través de una cámara. La obra refiere el asombro y el anhelo del observador, quien capta lo que el emisor desea tematizar y no indefectiblemente lo que el receptor construye en base al referente cultural, generando expectativas y anhelos por ese otro mundo que ve desde la perspectiva limitada e impuesta que el emisor del mensaje diseña. Instantáneas de la realidad. En el fondo se observa un ojo que capta todo lo que se sucede, que podría interpretarse como el subconsciente de la Pachamama, quien aun cuando aparenta estar sumida en el silencio y la modestia, en la realidad capta la totalidad del entorno. En el grafiti la Pachamama está triste y ambos personajes se ubican de espalda; lo que se interpreta como el alejamiento entre el ser humano y la Pachamama, derivando en el desequilibrio en la relación hombre/naturaleza. Por lo tanto, se estaría tocando un tema vigente; como es el medio ambiente. Según Oquendo (2019), los grafitis permiten expresar opinión y crítica sobre temas que afectan al artista y su entorno, en este caso se observa el distanciamiento de la relación con la naturaleza y cómo los más jóvenes anhelan lo que frece el mundo visto desde la diminuta perspectiva que ofrece un lente, ignorando la magnificencia del entorno.

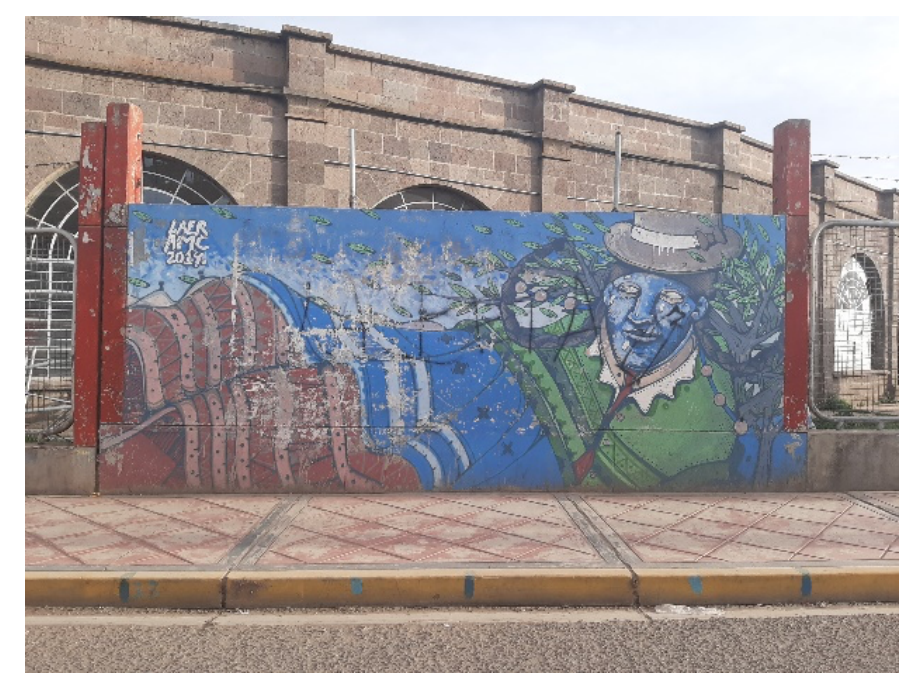

Figura 7. Grafiti de tipología, en el muro del estadio Enrique Torres Belón de Puno. Fotografía tomada por el investigador. 
Esta obra (figura 7) coincide con la anterior en el ámbito del surrealismo en el desdoblamiento de una mujer andina como representación del paisaje. A diferencia del grafiti anterior, en esta obra la Pachamama o madre tierra es representada con el rostro de una mujer andina alegre y de su cuerpo emanan los ríos y se posicionan las áreas de siembra, manifestando la alegría de la naturaleza en brindar sus frutos. La obra refiere a los fundamentos de la filosofía andina, aquella que expresa la relación complementaria que debe existir entre la naturaleza y el ser humano. Sobre el tema diversos autores señalan: La Pachamama es una deidad, la cual no tiene ubicación espacial, está en todos lados, que promueve la liberación del mal, la desigualdad e injusticia en el ser humano (Ortega, 2018), y posibilita el desarrollo humano de la consciencia espiritual, cultural (Gómez, 2018) para un diálogo y encuentro inter-cultural y ecuménico (Ortega, 2018).

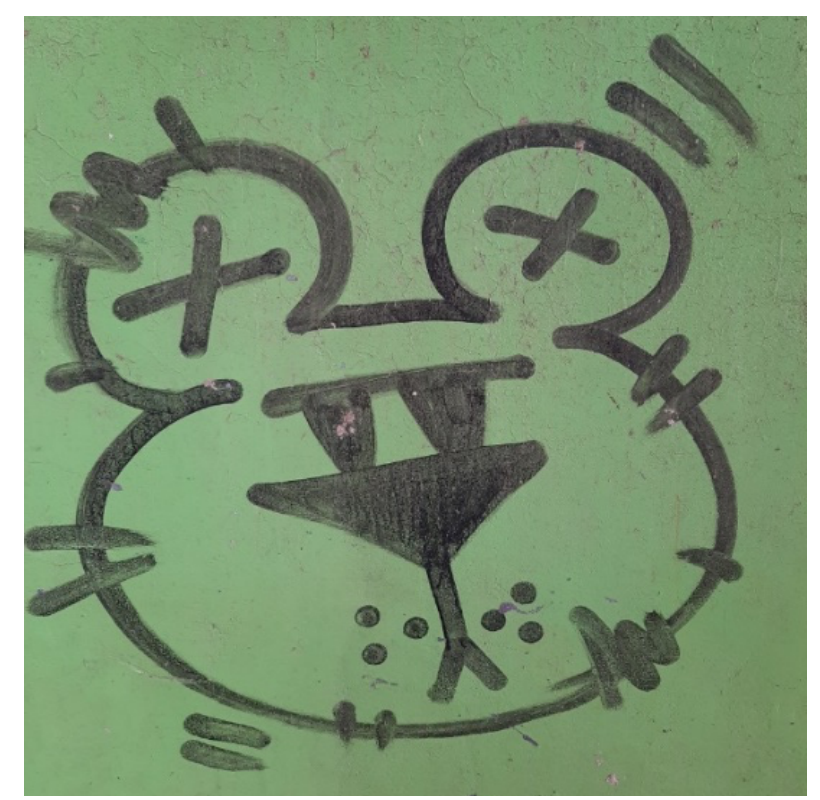

Figura 8. Grafiti con códigos visuales de grupos. Fotografía tomada por el investigador.

Existen grafitis como es el caso de la figura 8, que es representada, para expresar determinados códigos visuales que son propias de grupos de jóvenes y adolescentes. Ello es cónsono con lo planteado por Ramírez, et al., (2017) quienes señalan que el grafiti es un proceso cultural y semiótico creado por los jóvenes quienes, a través del arte le otorgan un significado a su cotidianidad, legitimando mediante el arte sus formas de vivir. Este tipo de grafiti es una constante en diversos espacios de la ciudad de Puno; como elemento 
identificador compartido que expresa un código cultural y semiótico reconocible por un grupo de personas, generando el sentimiento de pertenencia al grupo (Rivera, 2018).

\section{Registro sobre los espacios donde se puede apreciar trabajos de grafitis.}

Según Cumpa (2019) para un grafitero, cualquier superficie es buena para expresar su obra: una pared abandonada, la banca de un parque, el servicio higiénico público, el tronco de un árbol, la ventana de la casa de un vecino, o cualquier otro lugar (pag. 80). Con relación a los espacios que han tomado los grafiteros, en la ciudad de Puno, se limitan a espacios públicos como es el caso de los muros de la zona sur y norte del estadio Enrique Torres Belón, ubicada en el barrio porteño. En el estadio existen al menos diez grafitis, y se aprecian algunos rastros de grafitis antiguos deteriorados por los efectos del clima y la superposición de nuevos grafitis.

El carácter ilegal de esta expresión artística, deriva en el repintado regular de los espacios borrando los grafitis antiguos por lo que se observa que hay capas de pintura y en ciertas partes se avizoran vestigios de grafitis anteriores. Otro espacio icónico donde incursionaron los grafiteros de Puno es el Jirón Progreso, del barrio Bellavista, allí se ubica un centro recreacional para practicar skateboard, entre otras actividades propias de los niños y adolescentes. En este espacio los artistas realizaron varios grafitis, donde prevalecen los trazos con mensajes, tags, mensajes de amor y violencia, de una mera desordenada y sobrepuesta lo que se denomina tag bombing. En Jirón Progreso destacan dos grafitis que se refieren uno a la Pachamama (figura 7), y el otro a la cultura andina y su simbología. En el lado norte del barrio Laycacota de la ciudad de Puno hay algunos tags, pero la cantidad no es significativa. En el muro norte del hospital Manuel Núñez Butrón, se distinguen dos tags. Aundo a ello se distingue la presencia de grafitis en los muros de varias instituciones educativas, como es el caso del colegio María Auxiliadora, Gran unidad San Carlos, José Antonio Encinas, entre otras.

La causa de la poca incursión de grafitis en la ciudad de Puno se atribuye a la penalización y la recurrente limpieza de paredes por autoridades públicas. Además, la utilización de las paredes en el despliegue de anuncios publicitarios al servicio de eventos folklóricos, partidos políticos y demás actividades públicas y privadas desplazan al grafiti como resultado de la superposición de material gráfico sobre los grafitis. Otro elemento que se suma a las cusas del carácter efímero de los grafitis en Puno, se refiere a la calidad de la 
base que sirve de soporte a la obra como a la calidad de la pintura utilizada, que limita el tiempo de exposición antes que las inclemencias climáticas afecten parcial o totalmente la obra.

\section{Discusión}

La penalización del grafiti y los retos que implica el desempeño de este género artístico reduce la cantidad de creadores quienes se dedican a esta forma de expresión. Los costos de los materiales para la creación de obras cuya trascendencia es incierta, influye sobre la disposición de los artistas para crear obras cuya exhibición bien puede limitarse a escasas horas. En la ciudad de Puno no se conocen grupos de artistas grafiteros o colectivos crew que realice este tipo de arte urbano; por lo que no se puede identificar códigos comunicativos que diferencian las diversas creaciones (Reyes, 2012) ni que adscriban a las creaciones con una identidad propia en la calle (Cabrera, 2015).

En los grafitis descritos se perciben diversas imágenes de carácter figurativo y simbólico característicos de la cultura incaica, fundamentalmente los referidos a la Pachamama. Las connotaciones de las obras tienden hacia la polisemia confluyendo lo ingenuo y/o tradicional con lo moderno y contemporáneo. Cumpa, (2019) en se sentido refiere el mayor alcance de las obras polisémicas por cuanto son susceptibles de interés e interpretación por un público más vasto. Paradójicamente, esta polisemia se convierte en su fortaleza cuando de universalizar su circulación se trata. Debe admitirse que, por lo general, son los grafitis de carácter social y político los que mayor impacto causan a nivel mundial. La técnica dominante en la ejecución de los grafitis de Puno, se inscribe en la tendencia mundial del uso de aerosoles por los artistas urbanos, sin demeritar el uso de técnicas tradicionales de pincel, brocha e incluso lápiz o tiza.

\section{Conclusiones}

Los espacios más representativos de las obras grafiteras de Puno se localizan en el estadio Enrique Torres Belón, lados norte y sur y, en el Jirón Progreso. Sobre la tipología en los grafitis de la ciudad de Puno, se encontró tres tipos; el "wild style”, o estilo salvaje, que se caracteriza por que hay un desorden y sus terminaciones son con flechas, además se encontró "Grafiti tags con outlines" o firmas con contornos externos; por último, están los tags que se encuentran en un mayor porcentaje. Las corrientes artísticas que se lograron identificar como influyentes sobre las obras de los grafiteros de Puno se encuentran el 
simbolismo, realismo, surrealismo y abstracto, ya fuere como corriente dominante o como expresión sincrética de dos o más corrientes.

La cosmovisión andina se hace presente en las obras de los grafiteros de Puno en la recurrente convocatoria de la mítica Pachamama en reflexión constante sobre su interacción con el hombre y cómo se expresa esa interrelación en escenarios disimiles de reciprocidad y/o antagonismo. Los paisajes andinos aparecen reiteradamente ya fuere como escenario donde se sucede la interacción entre los protagonistas de la obra o cómo alegorías a la cultura originaria, recurriendo a figuras mitológicas o deidades del acervo cultural incaico.

\section{Referencias}

Agramunt (16 de Agosto de 2017). ArtEmotion. Obtenido de https://www.artemotion.art/el-surrealismo-poder-de-los-suenos-y-liberacion-de-laimaginacion/

Anchundia, J y Chang (16 de Agosto de 2018). EL GRAFITI COMO CRÍTICA SOCIAL EN GUAYAQUIL. Obtenido de https://www.artemotion.art/el-surrealismo-poderde-los-suenos-y-liberacion-de-la-imaginacion/

Ariaza, E., \& Martinez, R. (2016). "Hacer de la calle un Museo de la calle" el Garfiti y sus Actores en una Colonia Popular de Ecatepec, Estado de Máxico. Desacatos, 110129. Obtenido de http://www.scielo.org.mx/pdf/desacatos/n51/2448-5144desacatos-51-00110.pdf

Barzuna, G. (2005). Grafiti: la voz ante el silencio. Letras, (37). Obtenido de: file://C:/Users/user/Downloads/Dialnet-Graffiti-5476038.pdf

Cabrera, M. S. (2015). Urbanismo y arte no convencional: el garfiti en Cuenca Ecuador. Tesis de posgrado, Universidad de Cuenca. Obtenido de http://dspace.ucuenca.edu.ec/bitstream/123456789/22861/1/TESIS.pdf

Campohermoso Rodríguez, O. F., Soliz Soliz, R. y Campohermoso Rodríguez, O. (2015). Lógica Aimara Trivalente Y Cosmovisión Andina. Cuadernos Hospital de Clínicas, 56(2), 89-97. Obtenido de: 
http://www.scielo.org.bo/scielo.php?script=sci_arttext\&pid=S1652-

67762015000200019\&lng=es\&tlng=es.

Cruz Salazar, T. (2008). Instantáneas sobre el grafiti mexicano: historias, voces y experiencias juveniles. Última década, 16(29), $137-$

157. https://dx.doi.org/10.4067/S0718-22362008000200007

Cumpa, L. (2019). Expresion del Grafiti en el Espacio Urbano de Lima. Communifé, 79-

90. Obtenido de

http://www.unife.edu.pe/publicaciones/revistas/compunicacion/comunife16/EXPR ESION\%20DEL.pdf

De Diego, J. (1997). La estética del grafiti. En Departamento de Historia del Arte, Universidad de Zaragoza. Recuperado de: https://www.grafiti.org/faq/diego.html

García, J. (2016). Concientización a los miembros de la comunidad el Cóndor de la ciudad de Guayaquil. Tesis de pregrado, Pontificia Universidad Javeriana, Guayaquil. Obtenido de

Gómez, E. (27 de Septiembre de 2018). Fundación vivo sano. Obtenido de https://www.vivosano.org/buen-vivir-el-arte-de-vivir-en-armonia-con-la-madretierral

Gómez-Abarca, J. (2014). Grafiti: una expresión político-cultural juvenil en San Cristóbal de Las Casas, Chiapas, México. Revista Latinoamericana de Ciencias Sociales, Niñez y Juventud, 12 (2), 675-689. Obtenido de:

https://www.redalyc.org/pdf/773/77331488011.pdf

Grafiti, T. d. (2020). En hay tipos. Recuperado el 12 de enero de 2020, de https://haytipos.com/grafiti/

Hannerz, U. (1986). Explorando la ciudad. Madrid: Fondo de Cultura Económica.

Hernández, L. (2016). Mujeres y grafiti en México: algunas reflexiones sobre género y juventud. Elsevier. Obtenido de http://biblioteca.clacso.edu.ar/Colombia/alianzacinde-umz/20140916113611/jesusgomez.pdf

Hernández, R., Fernández, C., \& Baptista, M. d. (2014). Metodología de la investigación. México D.F.: Mc Graw Hill.

Hidalgo, L. (2019). Al ser una manifestación artistica urbana, los grafiteros expresan lo que piensan sin pelos en la lengua. Tesis de posgrado, Universidad de Palermo, 
Guayaquil. Obtenido de

https://www.palermo.edu/dyc/maestria_diseno/pdf/tesis.completas/34\%20Camar go.pdf

Lopera, Á. (2016). Intervención del espacio público: percepción ciudadana del grafiti. Encuentros.

López, A.J. (2018). Pésimo: el encuentro entre lo onírico y los rostros cotidianos de Latinoamérica. Cartel Urbano. obtenido de: https://cartelurbano.com/arte/pesimo-elencuentro-entre-lo-onirico-y-los-rostros-cotidianos-de-latinoamerica

Melell, A. C. \& Iniciativas para la Identidad y la Inclusión, A. C. (2011). La identidad estigmatizada: Jóvenes graffiteros, derechos humanos y politicas públicas en San Cristóbal de Las Casas, Chiapas. 2009-2010. San Cristóbal de Las Casas: Inicia

Oquendo, C. (2019). Lima Mural Project: El arte urbano que le pone color a Lima. diners. Obtenido de https://dialnet.unirioja.es/descarga/articulo/4323702.pdf.

Ortega, A. (19 de Julio de 2018). LoyolaAndnews. Obtenido de http://www.loyolaandnews.es/filosofia-andina/

Quecedo, R., \& Castaño, C. (2002). Introducción a la metodología de investigación cualitativa. Psicodidáctica, 9.

Quiroga, F. (Abril de 2019). Ergosfera. Obtenido de http://www.ergosfera.org/archivo/grafitis_pintadas.htm

Ramirez, M., Rodriguez, L. V., De los Angles, M. A., \& Rozo, H. A. (2017). El Grafiti como Artefacto Comunicador de las Ciudades: Una Revision de Literatura. Encuentros, 77-89. doi:DOI: http://dx.doi.org/10.15665/re.v15i1.812

Ramirez, R. (2013). Identidad: Construción Social y la Representacion en le Grafiti. Tesis de pregardo, Universidad Pedagogica nacional Unidad 092, Ajusto, D.F., Ajusto, D.F. Obtenido de http://200.23.113.51/pdf/30291.pdf

Reyes, F. (2012). Grafiti ¿Arte o vandalismo? Pensar la Publicidad, 53-70. Obtenido de https://revistas.ucm.es/index.php/PEPU/article/download/40636/38962/0. 
Rivera, R. (2018). Comunicarse por la calle con Grafiti. Contribuciones a las Ciencias Sociales. Obtenido de

http://sedici.unlp.edu.ar/bitstream/handle/10915/39176/Documento_completo.pd f?sequence $=1$

Tupac, E. (2020). Obras. Obtenido de: https://www.elliottupac.com/

Wilson, J Y Kelling, G.(1982). Broken Windows: The police and neighborhood safety. The Atlantic Montley. Recuperado de: https://media4.manhattaninstitute.org/pdf/_atlantic_monthly-broken_windows.pdf

Enviado: 2020-03-04

Aceptado: 2020-12-07 